\title{
Role of the transcriptional factors FOXO1 and PPARG on gene expression of SLC2A4 in endometrial tissue from women with polycystic ovary syndrome
}

\author{
Karla Kohan ${ }^{1}$, Rodrigo Carvajal ${ }^{1}$, Fernando Gabler $^{2}$, David Vantman ${ }^{3}$, Carmen Romero ${ }^{1,3}$ \\ and Margarita Vega ${ }^{1,3}$ \\ ${ }^{1}$ Laboratory of Endocrinology and Reproductive Biology, University of Chile Clinical Hospital, Santos Dumont \# 999, \\ Independencia, Santiago 838-0456, Chile, ${ }^{2}$ Department of Pathology, School of Medicine, San Borja Arriarán Clinical \\ Hospital, University of Chile, Santiago 832-0000, Chile and ${ }^{3}$ Department of Obstetrics and Gynecology, School of \\ Medicine, University of Chile Clinical Hospital, Santiago 838-0456, Chile
}

Correspondence should be addressed to M Vega at Laboratory of Endocrinology and Reproductive Biology, University of Chile Clinical Hospital; Email: mvega@med.uchile.cl; mvega@redclinicauchile.cl

\begin{abstract}
Fifty to seventy percent of patients with polycystic ovary syndrome (PCOS) present hyperinsulinemia. On the other hand, reports indicate that forkhead box class $\mathrm{O} 1$ (FOXO1) and peroxisome proliferator-activated receptor- $\gamma$ (PPARG) are involved in the insulin signaling pathway, regulating the gene expression of SLC2A4 (GLUT4). The negative effect of FOXO1 over PPARG transcription disappears when FOXO1 is phosphorylated (p-FOXO1) and excluded from the nucleus, whereas PPARG can suppress gene expression of SLC2A4. Scarce knowledge is available in endometrium of women with PCOS and hyperinsulinemia (PCOSE h-Ins) about the role of these factors. We aimed to evaluate whether the endocrine and metabolic status of PCOS modify the levels of gene and protein expression of FOxO1, PPARG, and SLC2A4 in the endometria from hyperinsulinemic PCOS women compared with controls. In endometria from control $(C E, n=7)$ or PCOSE h-Ins $(n=7)$, we determined the subcellular location and protein levels of p-FOXO1Ser319 and FOXO1/FOXO4 by immunohistochemistry and western blot respectively; gene and/or protein levels of PPARG and SLC2A4 were evaluated by RT-PCR and/or western blot. Cytoplasm location for FOXO1 and p-FOXO1Ser319 was immunodetected in both groups of endometria, showing significantly higher staining in PCOSE $h$-Ins for these proteins $(P<0.05)$. In PCOSE h-Ins, gene and protein levels of PPARG were significantly higher than in CE, whereas SLC2A4 mRNA was decreased $(P<0.05)$. In conclusion, the derepression of PPARG transcription by the high levels of p-FOXO1Ser319 could partially account for the lower levels of SLC2A4 found in PCOSE h-Ins, suggesting an alteration of the endometrial function in these patients.

Reproduction (2010) $\mathbf{1 4 0} 123-131$
\end{abstract}

\section{Introduction}

Polycystic ovary syndrome (PCOS) is a disease characterized by an endocrine metabolic disorder and is considered to be the most common alteration among women in fertile age, having prevalence between 5 and 10\% (Dunaif 1997, Salley et al. 2006). The women who suffer from this syndrome present ovarian dysfunction generating hyperandrogenism and/or hyperandrogenemia (Pugeat et al. 2000, Azziz et al. 2006). This syndrome is related to obesity in $30 \%$ of the cases (Calle \& Kaaks 2004) and to insulin resistance in $60-75 \%$ of them (Froment et al. 2006, Giudice 2006). Therefore, these patients are at a high risk of developing cardiovascular diseases and diabetes mellitus (Ehrmann et al. 2006). PCOS has also been linked with infertility, abortions, and recurrent miscarriages; in fact, women with PCOS present a higher significant miscarriage rate
(40-50\%) in contrast with normal women $(20 \%$; Porter \& Scott 2005, Giudice 2006).

Besides the ovarian dysfunction in PCOS, other tissues of the organism are also affected, including the endometrium. To fulfill its function, the endometria need high supply of energy, particularly from glucose intake and its posterior metabolism. In this aspect, results from our laboratory and other groups indicate that some molecules involved in the insulin signaling pathway could be altered in the endometrium of women with PCOS (PCOSE; Mioni et al. 2004, Avellaira et al. 2006). In fact, we have previously shown that phosphorylation of AKT at Ser473 is increased in the PCOSE (Avellaira et al. 2006, Villavicencio et al. 2009).

In most tissues, glucose uptake is achieved by glucotransporters, some of which are insulin dependent, like SLC2A4 (GLUT4). It has been reported that in 
PCOSE, there is a decrease in the transcript and protein of SLC2A4, particularly in the endometria from obese and hyperinsulinemic PCOS women (Mioni et al. 2004). The decreased levels of SLC2A4 may be due partially to changes in molecules that regulate the expression of this glucotransporter. In this regard, it is known that the peroxisome proliferator-activated receptor (PPAR) and the so-called forkhead box class $\mathrm{O}$ (FOXO) transcription factors are important to regulate the cell homeostasis of glucose (Armoni et al. 2007). PPARs are members of a superfamily of nuclear receptors, and three known PPAR isoforms $-\alpha, \beta / \delta, \gamma-$ have been described (Yu \& Reddy 2007). The isoform $\gamma$ (PPARG) is expressed mainly in tissues that respond to insulin, having a role in regulating glucose intake (Jermendy 2007).

As mentioned, the FOXO proteins are part of the family of transcription factors forkhead-winged helix box. The members of this family include isoforms FOXO1, FOXO3a, and FOXO4. The protein FOXO1 is the most abundant isoform in insulin-sensitive tissues such as liver, pancreas, and adipose tissue (Gross et al. 2008). The function of FOXO1 is negatively regulated by AKT, exhibiting three sites for AKT phosphorylation, Thr24, Ser256, and Ser319. When phosphorylated, FOXO1 is located at the cytoplasm level where it is inactivated (Armoni et al. 2006, Lengyel et al. 2007), and degraded by the proteasome (Nakae et al. 2008). On its basal state (not phosphorylated), FOXO1 molecules are mainly detected at the nuclear level, where they bind directly to the promoter of PPARG, resulting in suppression of its transcription (Armoni et al. 2007). The action of PPARG as a transcription factor involves the heterodimerization with retinoid $X$ receptor. Transcriptional activation occurs in a ligand-dependent manner, because the binding of ligand could allow the recruitment of a coactivator complex (Picard \& Auwerx 2002, Yu \& Reddy 2007, Ziouzenkova \& Plutzky 2008), whereas, in the absence of ligand, corepressors are recruited (Ricote \& Glass 2007). Therefore, according to the mechanism described above, PPARG regulates the expression of SLC2A4 by activating or repressing its transcription (Karnieli \& Armoni 2008). So far, no information is available about the expression levels of these transcription factors involved in insulin signaling and regulation of SLC2A4 mRNA transcription in endometria from women bearing PCOS. Therefore, the aim of the present investigation was to determine whether the levels of the transcription factors FOXO1 and PPARG in PCOSE differ from those in control endometria.

\section{Results}

\section{Clinical and metabolic characteristics of subjects}

The clinical and metabolic characteristics of the two groups of women are summarized in Table 1 . The higher body mass index observed in PCOS women group is
Table 1 Clinical and endocrine characteristics of control women (CE) and women with polycystic ovary syndrome (PCOS) and hyperinsulinemia (PCOSE h-Ins).

\begin{tabular}{lcc}
\hline & CE & PCOSE h-Ins \\
\hline Age (years) & $39.72 \pm 1.23$ & $27.16 \pm 0.62^{*}$ \\
BMl & $29.69 \pm 1.95$ & $32.71 \pm 0.93$ \\
$\mathrm{E}_{2}(\mathrm{pg} / \mathrm{ml})$ & $73.78 \pm 22.37$ & $62.2 \pm 3.45$ \\
$\mathrm{P}_{4}(\mathrm{ng} / \mathrm{ml})$ & $0.69 \pm 0.28$ & $0.612 \pm 0.06$ \\
$\mathrm{~A}_{4}(\mathrm{ng} / \mathrm{ml})$ & $1.57 \pm 0.22$ & $2.84 \pm 0.19^{*}$ \\
$\mathrm{~T}(\mathrm{ng} / \mathrm{ml})$ & $0.44 \pm 0.06$ & $0.81 \pm 0.05^{*}$ \\
$\mathrm{SHBG}(\mathrm{mmol} / \mathrm{l})$ & $51.67 \pm 9.53$ & $24.24 \pm 2.08^{*}$ \\
FAI & $3.73 \pm 0.74$ & $13.5 \pm 1.58^{*}$ \\
\hline
\end{tabular}

$* P<0.05$ vs $C E$.

inherent to the syndrome. In addition, all the PCOS women included in this study presented with hyperinsulinism and hyperandrogenism, and the excessive ovarian androgen production besides the decreased sex hormone-binding globulin (SHBG) blood level leads to a significantly higher free androgen index in PCOS women.

\section{Protein expression for phosphorylated and unphosphorylated forms of FOXO}

We evaluated the protein levels of phosphorylated FOXO1 at Ser319 by immunohistochemistry, whereas, for the detection of unphosphorylated FOXO1, we used immunohistochemistry and western blotting. The antibody used for the detection of FOXO1 in the western blotting also recognizes $\mathrm{FOXO} 4$ isoform, although with a higher migration pattern than FOXO1. For the immunohistochemistry analysis, this antibody might recognize the two isoforms of FOXO. In the western blot analysis, no differences were observed between groups in the levels of FOXO1 protein (CE: $0.067 \pm 0.01$ versus PCOSE h-Ins: $0.088 \pm 0.03$ arbitrary unit (AU; Fig. 1A) or FOXO4 (CE: $0.042 \pm 0.005$ versus PCOSE h-Ins: $0.037 \pm 0.006 \mathrm{AU}$; Fig. 1B). The levels of FOXO1 and $\mathrm{FOXO} 4$ were normalized to the levels of $\beta$-actin. Although no differences were obtained between FOXO1 and FOXO4 in the studied groups, the relative levels of FOXO1 were $60 \%$ higher than FOXO4 for CE and 100\% higher for PCOSE h-Ins, suggesting a more important role for FOXO1 in these tissues.

Besides the assessment of the protein levels by western blot analysis, we were most interested in knowing the subcellular location of FOXO1/FOXO4 and p-FOXO1 Ser319. The immunohistochemical evaluation (Fig. 2) showed that in the PCOSE and hyperinsulinemia (PCOSE h-Ins), FOXO1/FOXO4 presented a strong staining in the cytoplasm of epithelial cells (Fig. 2C and E). The p-FOXO1Ser319 protein was located mainly in the cytoplasm of epithelial and stromal cells of endometria from control (Fig. 2D) and PCOS women (Fig. 2F). In the epithelial compartment, the protein levels of FOXO1 were significantly higher in the endometria of patients 

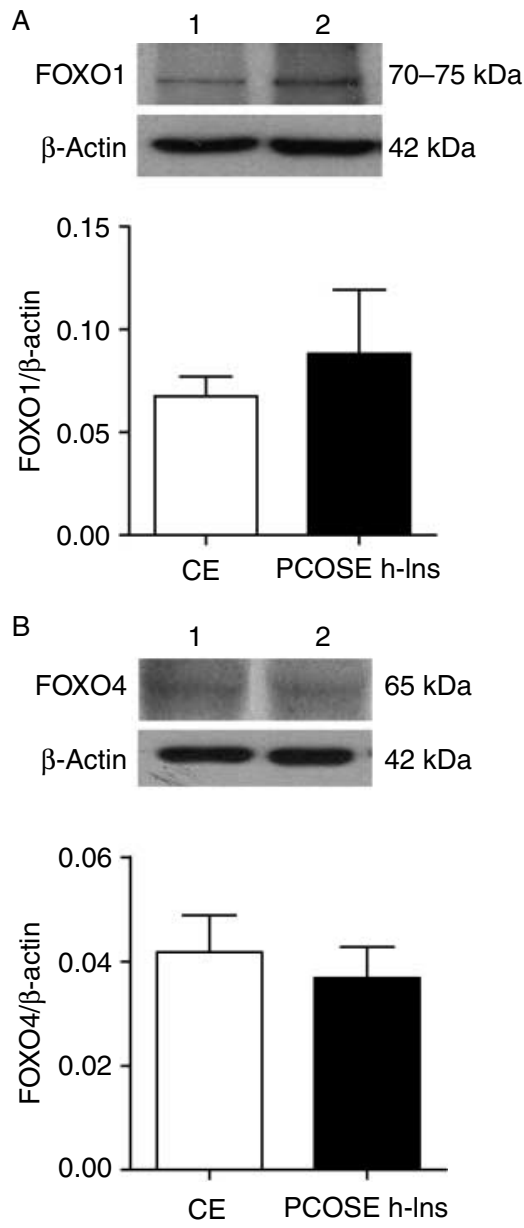

Figure 1 Western blot analysis of protein levels of FOXO1 and FOXO4 in endometria from CE and PCOSE h-Ins. Equal amounts of protein $(50 \mu \mathrm{g})$ were loaded in each lane. FOXO1 (A) was detected as a band with a molecular mass between 70 and $75 \mathrm{kDa}$, and FOXO4 (B) was detected as a band with a molecular mass of $65 \mathrm{kDa}$. Band intensities were quantified by scanning densitometry and normalized to intensities observed for $\beta$-actin as internal control. Lane 1, CE; lane 2, PCOSE h-Ins. The results are expressed as arbitrary units (AUs), and the values shown are means \pm S.E.M. in CE $(n=7)$ and PCOSE h-Ins $(n=7)$.

with PCOS compared with controls $(P<0.05$; Fig. 2G). The same was observed for p-FOXO1Ser319, where a $40 \%$ of higher protein levels was observed $(P<0.05$; Fig. 2H). Nevertheless, in the stromal compartment, no differences were observed between the studied groups for the protein in its phosphorylated or nonphosphorylated state.

\section{Gene and protein levels of PPARG}

The next step was to evaluate the transcription of PPARG mRNA in both types of endometria. We observed that the PCOS hyperinsulinemic endometria exhibited significantly higher levels of PPARG mRNA compared with those found in control proliferative endometria $(P<0.05$; Fig. 3A). Similarly, the western blot analysis revealed a significant increase of PPARG protein levels in the PCOSE h-Ins compared with controls $(P<0.05$; Fig. 3B). In addition, a comparison between the gene levels of PPARG in control proliferative and secretory phase was made. It was observed that the mRNA of $P P A R G$ is expressed in the endometrium of healthy women in both phases of the menstrual cycle, and found no significant differences between them (data not shown).

\section{mRNA levels of SLC2A4}

The RT-PCR analysis for SLC2A4 showed a significant decrease in the levels of transcript in endometria from women with PCOS and hyperinsulinemia compared with control endometria ( $P<0.05$; Fig. 4). These results are in agreement with the diminished protein levels of SLC2A4 observed in PCOSE h-Ins reported previously (Fornes et al. 2010).

In addition, we performed a correlation study between protein levels of PPARG and SLC2A4 mRNA in PCOSE h-Ins patients, obtaining a negative and significant statistical correlation $(r=-0.78 ; P=0.037)$, suggesting that high protein levels of PPARG cause a decrease in $S L C 2 A 4$ transcript.

\section{Discussion}

It is well known that a high percentage of women with PCOS present hyperinsulinemia besides their hyperandrogenism, which could alter the function of numerous tissues (Diamanti-Kandarakis \& Papavassiliou 2006), including the endometrium. Our group has previously shown that the endometria from PCOS women exhibit several abnormalities, leading to failure in uterine receptivity (Quezada et al. 2006), endometrial homeostasis, and steroid bioavailability (Maliqueo et al. 2003b, Avellaira et al. 2006, Bacallao et al. 2008, León et al. 2008, Villavicencio et al. 2009). The present investigation aimed to gain knowledge about the regulation of the transcription of SLC2A4 in PCOSE h-Ins. To our knowledge, this is the first study where the protein levels of the transcription factors PPARG and FOXO1 and its phosphorylated form were evaluated in endometrial tissue from PCOS women.

Little information is available related to the regulation of SLC2A4 transcription in human endometrium. Experimental evidences show that in adipocytes (Armoni et al. 2007), the transcription factors FOXO1 and p-FOXO1Ser319 are involved in the insulin pathway by regulating the transcription of PPARG. As known, FOXO1 is located mainly at the nuclear level where it exerts a negative action on the transcription of PPARG by binding to the promoter. When FOXO1 is phosphorylated, it migrates to the cytoplasm and the transcription of PPARG proceeds. FOXO1 can be phosphorylated in several residues and by several kinases, including AKT 


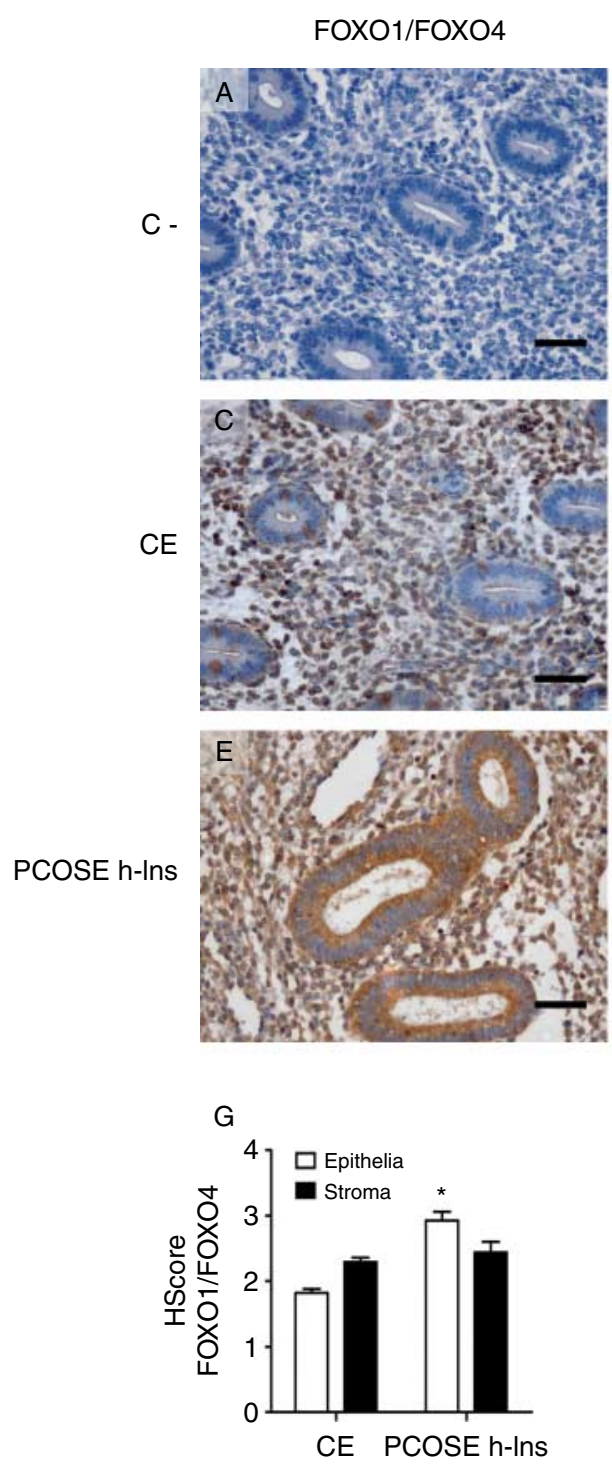

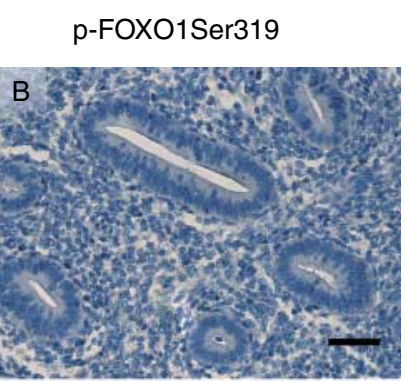
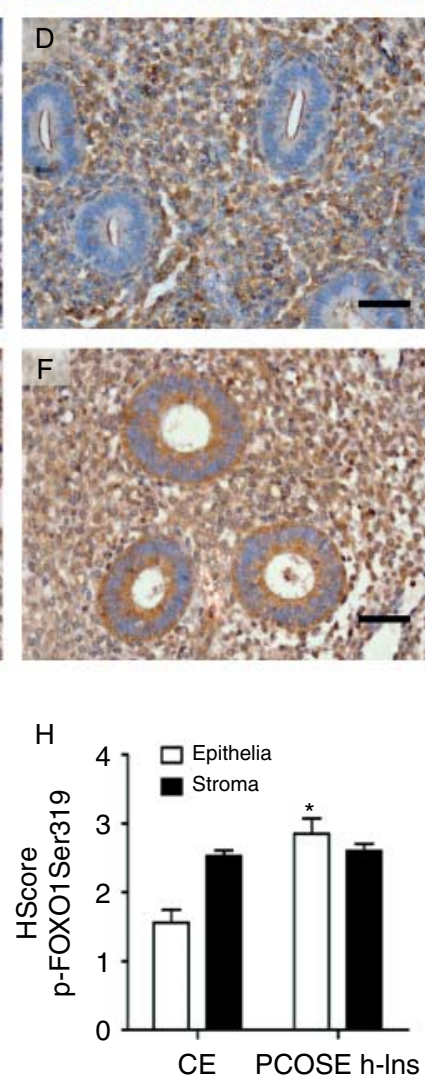

Figure 2 Immunohistochemical detection for FOXO1/ FOXO4 and p-FOXO1Ser319 proteins in paraffin wax sections of proliferative endometria obtained from normal women (CE, $n=7)$, and PCOSE with hyperinsulinemia (PCOSE h-Ins, $n=7$ ). Positive staining was detected in epithelial and stromal cells of all studied endometria for both antigens. As a negative control, the primary antibody was omitted. A, represents negative control for FOXO1/FOXO4; $\mathrm{B}$, negative control for p-FOXO1Ser319; C, CE for FOXO1/ FOXO4; D, CE for p-FOXO1Ser319; E, PCOSE h-Ins for FOXO1/FOXO4; F, PCOSE h-Ins for p-FOXO1Ser319; $\mathrm{G}$, semiquantification of FOXO1/FOXO4; $\mathrm{H}$, semiquantification of FOXO1Ser319. Magnification $400 \times$. Scale bars represent $50 \mu \mathrm{m}$. The immunostaining was measured by HScore (HS), expressed as $\mathrm{HS} \pm$ S.E.M. $* P<0.05$ versus $C E$ compared with PCOSE h-Ins. Calculation of HScore is described in Materials and Methods. and MAPK (Asada et al. 2007). In the present study, we analyzed the levels of basal FOXO1/FOXO4 and phosphorylated FOXO1 in Ser319, site of phosphorylation by activated AKT (Armoni et al. 2006, Nakae et al. 2008). We found higher levels of FOXO1/FOXO4 and p-FOXO1Ser319 particularly in epithelial cells of PCOSE h-Ins, as assessed by immunohistochemistry, where the phosphorylated form was located mainly in the cytoplasm, in agreement with previous reports in adipose tissue (Armoni et al. 2007). Accordingly, our previous investigations (Avellaira et al. 2006, Villavicencio et al. 2009) demonstrated an increase in p-AKTSer473 in PCOSE that could account for the high levels of p-FOXO1Ser319. Nevertheless, when the protein levels of FOXO1 were analyzed by western blotting, no differences were found between the studied groups, probably due to the different methodologies used in each case. As already mentioned, in control endometria, the nonphosphorylated form of
FOXO1/FOXO4 was located mainly at the nuclear level in accordance with previous reports, whereas, in PCOSE h-Ins, this protein was found mainly in the cytoplasm of cells. Currently, we have no explanation for this finding, although it can be speculated that the cytoplasm location of FOXO1/FOXO4 in the pathological endometria could prevent its function as a negative regulator of PPARG transcription. On the other hand, our data cannot discard a role for $\mathrm{FOXO} 4$ in the regulation of insulin action in human endometria; nevertheless, the higher levels of FOXO1 than FOXO4 detected by western blot suggest an important regulatory role for FOXO1 in the insulinsignaling pathway present in this tissue.

Therefore, all together, these data indicate a positive transcriptional regulation over PPARG, and indeed we found elevated levels of its mRNA, as well as the protein, in endometria from hyperinsulinemic PCOS women. In addition, we observed no changes in the levels of the transcript and protein of PPARG in control 

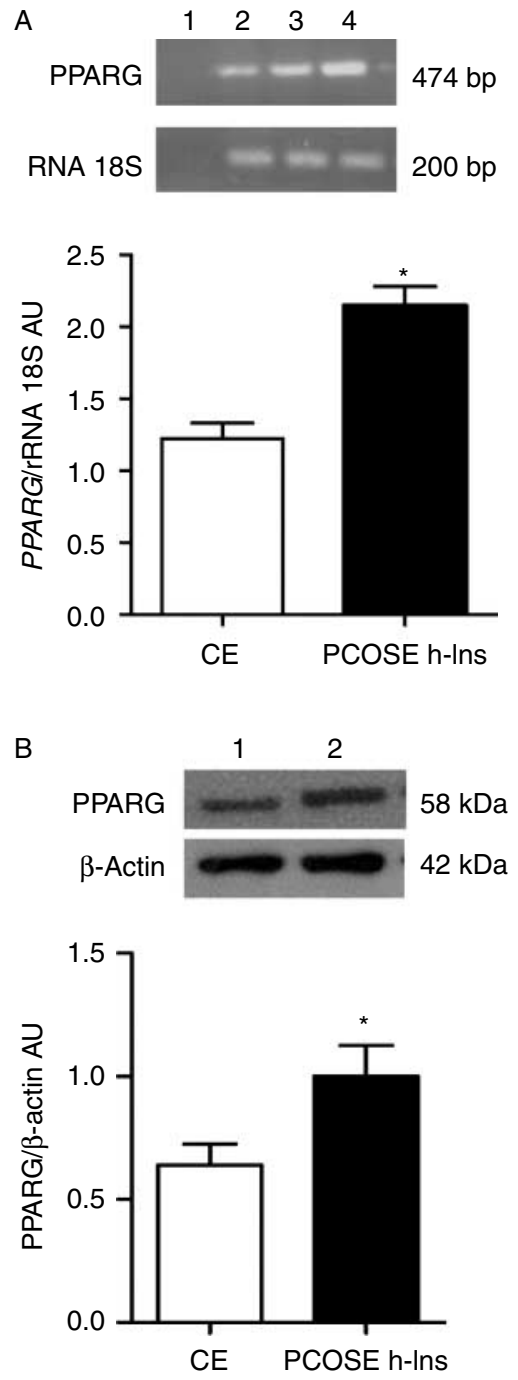

Figure 3 (A) Semiquantitation of mRNA levels for the transcriptional factor PPARG. Conventional RT-PCR was performed in human endometria: control (CE) and polycystic ovarian syndrome with hyperinsulinemia (PCOSE h-Ins). Representative gel is shown ( $2 \%$ agarose gel electrophoresis, staining with ethidium bromide). Lane 1, negative control; lane 2, muscular tissue as positive control; lane 3, CE; and lane 4, PCOSE h-Ins. (B) Western blotting for PPARG in human endometrial tissue. Equal amounts of endometrial protein were loaded in each lane. The protein PPARG was detected as bands with molecular mass of $58 \mathrm{kDa}$. Lane 1, CE; lane 2, PCOSE h-Ins. The results are expressed as arbitrary units (AUs), and the values shown are mean \pm s.E.M. in CE $(n=7)$ and PCOSE h-Ins $(n=7) .{ }^{*} P<0.05$ in CE compared with PCOSE h-Ins.

endometria throughout the menstrual cycle (data not shown), which agrees with previous publications (Ota et al. 2006).

It has been described that in cultures of adipocytes, PPARG is capable of producing an inhibition of the transcription of SLC2A4 (Armoni et al. 2003). Therefore, the same situation could be occurring in the pathological endometria, where the decrease of SLC2A4 mRNA observed in the PCOSE h-Ins could be partially caused by the high levels of PPARG detected in these patients. These findings are in agreement with the negative correlation between these parameters observed in the present investigation.

Diverse studies have focused on the effects of thiazolidinediones (TZDs), synthetic hypoglycemic agents which are potent ligands of PPARG. The TZDs increase insulin sensitivity without increasing insulin secretion through the activation of multiple genes, including the upregulation of glucose transporter SLC2A4 (Al-Khalili et al. 2005). Despite the presence of documented favorable reproductive and metabolic effects of TZDs in PCOS population, their tissue-specific cellular effects are less clear (Froment \& Touraine 2006). Among these drugs, rosiglitazone represents a new generation of TZDs, which reduces the hyperandrogenism, besides the improvement of the fertility capacity, as well as, the metabolic profile in PCOS patients (Cataldo et al. 2001). Moreover, Jensterle et al. (2008) found in subcutaneous adipose tissue samples from women with PCOS that received either metformin or rosiglitazone for 6 months, a significant increase of SLC2A4 mRNA expression in both groups. Interestingly, after treatment, the frequencies of menstrual bleeding were significantly higher in both groups, suggesting that TZD may exert a direct effect in the endometria, as it has been demonstrated in other reproductive tissues (Seto-Young et al. 2005). In addition, Legro et al. (2007) studied the effects of metformin and/or rosiglitazone in the endometria of hyperandrogenic PCOS patients and found an
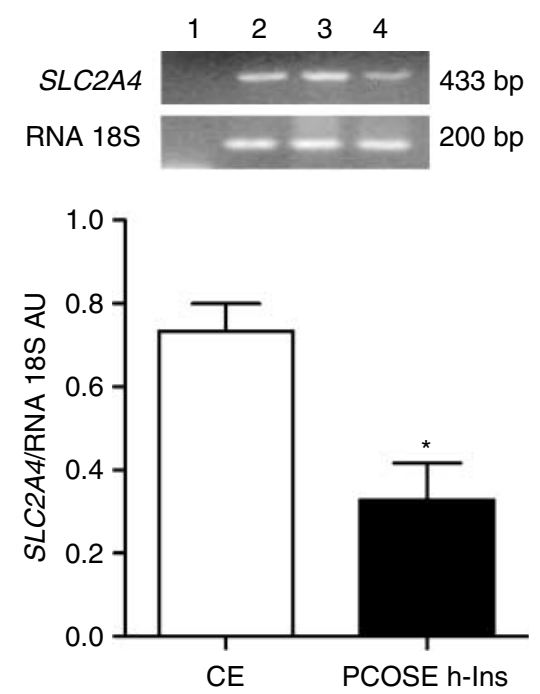

Figure 4 Analysis of SLC2A4 mRNA expression. Conventional RT-PCR was performed in human endometria: control (CE) and polycystic ovarian syndrome with hyperinsulinemia (PCOSE h-Ins). Representative gel is shown ( $2 \%$ agarose gel electrophoresis, staining with ethidium bromide). Lane 1, negative control; lane 2, muscular tissue as positive control; lane 3, CE; and lane 4, PCOSE h-Ins. The number of women evaluated was $n=7$ for each analyzed group. The results are expressed as mean \pm s.E.M. RNA ribosomal $18 \mathrm{~S}$ was used as the internal control: ${ }^{*} P<0.05$ versus CE. 
improvement in the prevalence of the secretory morphology, not excluding a local effect of these compounds in the ovary or the endometria of PCOS patients.

In summary, in the present investigation, we report the expression levels of FOXO1/FOXO4, PPARG, and SLC2A4 in the PCOSE h-Ins. We also present evidence that the potential problems of the metabolism of insulin and glucose could be due at least in part to alteration in the expression levels of these proteins in the PCOSE h-Ins. Therefore, we can conclude that high levels of p-FOXO1Ser319 and cytoplasm localization of nonphosphorylated FOXO1 cause a derepression in the transcription of PPARG, showing not only higher levels of its mRNA, but also the protein, which might be suppressing the expression of SLC2A4 gene, and consequently altering endometrial function in PCOS women.

\section{Materials and Methods}

This investigation was approved by the Clinical Hospital and School of Medicine, University of Chile Ethical Committees, and informed written consent was obtained from all subjects.

\section{Subjects}

Human endometria were obtained with a Pipelle suction curette from the corpus of the uteri of women with PCOS. Glucose and insulin levels were evaluated by an oral glucose tolerance test with 75-g load of glucose. In order to determine a hyperinsulinemic condition, we measured plasma glucose and insulin levels at $2 \mathrm{~h}$ post the load of glucose. The diagnosis of hyperinsulinemia was determined when the levels of insulin were 2 s.D.s of insulin concentration over the mean of the control group, as in previous studies (Maliqueo et al. 2003a, Fornes et al. 2010). The insulin values for the control group and PCOS h-Ins were 49.6 \pm 11.6 and $150.5 \pm 46.1 \mu \mathrm{lU} / \mathrm{ml}$ respectively. All women had normal glycemic values in the oral tolerance glucose test (basal glucose $<100 \mathrm{mg} / \mathrm{dl}$; glucose $120 \mathrm{~min}<140 \mathrm{mg} / \mathrm{dl}$ ). Also, all the PCOS women participants in this investigation had hyperandrogenism besides their hyperinsulinemia.

The studied groups were endometria from control women obtained during the proliferative phase of the menstrual cycle $(\mathrm{CE}, n=7)$ and endometria obtained from anovulatory PCOS women (PCOSE h-Ins, $n=7$ ). Control endometria were obtained from hysterectomy for benign causes, and they were selected in the proliferative phase because of the similar morphology between proliferative endometrium and PCOSE. None of the women, neither controls nor those with PCOS, had received hormonal therapy within 3 months prior to the recruitment into the study. The proliferative phase in CE and PCOSE was confirmed on the basis of histological dating and classification according to the Noyes criteria (Noyes et al. 1950) by an experienced pathologist.

The diagnosis of PCOS was made according to the Rotterdam Consensus (Rotterdam ESHRE/ASRM-Sponsored PCOS Consensus Workshop Group 2004) and to the Androgen Excess
Society criteria (Azziz et al. 2006) for the definition of PCOS. The exclusion criteria were women who presented with hyperprolactinemia (prolactin $>35 \mathrm{ng} / \mathrm{ml}$ ), hypothyroidism (TSH $>5 \mathrm{UI} / \mathrm{l}$ ), androgen-secreting tumors (total testosterone $>2 \mathrm{ng} / \mathrm{ml}$; DHEAS > $3600 \mu \mathrm{g} / \mathrm{ml}$ ), Cushing's syndrome (urine cortisol concentration $>150 \mu \mathrm{g} / 24 \mathrm{~h}$ and fasting plasma concentration of cortisol $>25 \mu \mathrm{g} / \mathrm{dl}$ ), congenital adrenal hyperplasia (17-OH progesterone $>2.5 \mathrm{ng} / \mathrm{ml}$ ) and women with diabetes or treatment with hormones and/or ovulation induction.

\section{Reagents}

The MABs for PPARG and $\beta$-actin were purchased from Abcam (Cambridge, MA, USA) and Sigma respectively. The polyclonal antibodies for FOXO1/FOXO4 and phosphorylated FOXO1 in Ser319 were obtained from Cell Signaling Technology (Beverly, MA, USA). Secondary antibodies (mouse monoclonal and rabbit polyclonal) were purchased from Amersham Biosciences (Amersham International). Protease inhibitor cocktail was obtained from Roche Molecular Biochemicals, BCA protein assay kit was obtained from Pierce (Rockford, IL, USA), and Histostain SP kit was obtained from Zymed Laboratories (San Francisco, CA, USA). TRIzol reagent and M-MLV RT were obtained from Invitrogen, and Taq DNA polymerase was obtained from Biotools (Madrid, Spain). Hormone determinations were assayed by commercial kits: serum testosterone, estradiol, and progesterone by solidphase, competitive chemiluminescent enzyme immunoassay (Ortho-Clinical Diagnostics, Johnson \& Johnson, High Wycombe, UK); androstenedione (A4) by RIA (Siemens, Los Angeles, CA, USA); SHBG concentration by Immulite and solid-phase chemiluminescent immunometric assay (Siemens, Llanberes, Gwynedd, UK).

\section{Immunohistochemistry}

Immunostaining for FOXO1/FOXO4 and p-FOXO1Ser319 was performed on $5-\mu \mathrm{m}$ sections of formalin-fixed, paraffinembedded endometrial biopsies. Tissue sections were deparaffinized in xylene and hydrated in a series of graded alcohol. The sections were incubated in antigen retrieval solution (10 mmol// sodium citrate buffer, $\mathrm{pH} 6.0$ ) at $96-98{ }^{\circ} \mathrm{C}$ for $20 \mathrm{~min}$. Endogenous peroxidase activity was prevented by incubating the samples in $3 \%(\mathrm{v} / \mathrm{v})$ hydrogen peroxide for $15 \mathrm{~min}$. Nonspecific antibody binding was prevented with specific blocker of the Histostain SP kit. Primary antibody of FOXO1/FOXO4 (1:75) and p-FOXO1Ser319 (1:75) was applied to the samples and incubated overnight at $4{ }^{\circ} \mathrm{C}$. Negative controls were analyzed on adjacent sections and incubated without primary antibody, as well as, with nonimmune species-specific antisera. The secondary antibody was a biotinylated antimouse/antirabbit immunoglobulin. The reaction was developed by the streptavidin-peroxidase system, and $3,3^{\prime}$ diaminobenzidine was used as the chromogen; counterstaining was carried out with hematoxylin. The slides were evaluated in an optical microscope Olympus BX51 (Olympus, Tokyo, Japan). The immunohistochemical evaluation for each protein was performed by a semiquantitative analysis described by Lessey et al. (1988) and validated in our 
laboratory (Castro et al. 2002, Villavicencio et al. 2009) named HScore (histochemical score, HS), which corresponds to: $\Sigma[P]$ $(i+1) / 100$, where $[P]$ is the percentage of positively stained cells and $i$ is the intensity of the staining on a scale of $0-3(0$, no stain; 1, low intensity; 2, mid intensity; and 3, higher intensity). Each protein was evaluated in the functional layer by three independent observers blinded to patient category, and the positive staining was assessed in at least 3000 cells per sample.

\section{Western blot analysis}

The endometrial tissue was homogenized in a lysis buffer (HEPES $20 \mathrm{mmol} / \mathrm{l}$, EDTA $2 \mathrm{mmol} / \mathrm{l}$, EGTA $2 \mathrm{mmol} / \mathrm{l}$, Triton 1\%, phenylmethylsulphonyl fluoride $5 \mu \mathrm{mol} / \mathrm{l}$, and $\mathrm{Na}_{3} \mathrm{VO}_{4}$ $50 \mu \mathrm{mol} / \mathrm{l}$ ) containing protease inhibitor cocktail (Roche). After centrifugation at $10000 \mathrm{~g}$ for $20 \mathrm{~min}$ at $4{ }^{\circ} \mathrm{C}$, protein concentrations were determined using the BCA protein Assay kit (Pierce). Total proteins $(50 \mu \mathrm{g})$ were denatured and fractionated using $8 \%$ one-dimensional SDS-PAGE, and transferred to nitrocellulose membrane (Bio-Rad). Membranes were blocked for $1 \mathrm{~h}$ in TBST (20 mmol/l Tris, $\mathrm{pH} \mathrm{7.6;}$ $137 \mathrm{mmol} / \mathrm{l} \mathrm{NaCl}$; and $0.1 \%$ Tween 20) containing 10\% (w/v) nonfat dry milk-TBST (for all markers). Subsequently, the membranes were washed three times for $5 \mathrm{~min}$ each in TBST, and then incubated with antibodies against PPARG (1:750) and FOXO1/FOXO4 (1:500) overnight with rocking at $4{ }^{\circ} \mathrm{C}$, and against $\beta$-actin $(1: 15000)$ for $1 \mathrm{~h}$ at room temperature. The membranes were then washed three times for $5 \mathrm{~min}$ each with TBST, followed by incubation for $1 \mathrm{~h}$ at room temperature with antimouse IgG peroxidase-conjugated species-specific (1:3000 for PPARG and 1:5000 for $\beta$-actin) or with antirabbit IgG peroxidase-conjugated species-specific (1:1500 for FOXO1/FOXO4), while rocking. After washing three times for 5 min each with TBST, the bound antibodies were detected with an enhanced chemiluminescence system (Amersham International) and analyzed by the program UN-SCAN-IT gel 4.1 (Silk Scientific Corporation, Orem, UT, USA). The protein levels were normalized by the levels of the protein $\beta$-actin and expressed as AUs.

\section{RNA isolation and semiquantitative RT-PCR}

Total RNA was isolated from endometrial tissue using TRIzol reagent according to the manufacturer's instructions. The concentration of RNA was determined spectrophotometrically (A260:A280), while the integrity of the RNA was determined by electrophoresis on a formaldehyde agarose gel under denaturing conditions. The RNA was visualized by adding ethidium bromide $(\mathrm{EtBr})$ to the sample before loading on the gel. The RNA was stored at $-80{ }^{\circ} \mathrm{C}$ until use. Two micrograms of total RNA were digested with DNase I and transcribed into cDNA by RT with M-MLV RT using random primers in a total volume of $25 \mu \mathrm{l}$. The PCR amplifications were obtained using gene-specific primers (Table 2). Ribosomal RNA 18S was used as an internal control. Semiquantitative RT-PCRs were achieved in the exponential linear zone amplification for each gene studied. The PCR conditions for PPARG were $2 \mathrm{mmol} / \mathrm{l} \mathrm{MgCl}_{2}, 0.20 \mathrm{mmol} / \mathrm{l}$ dNTPs, $0.750 \mathrm{U}$ of Taq DNA polymerase, and 25 pmol each primer; the PCR conditions for
Table 2 Primer sequences used for PCR of CDNA for the analysis of peroxisome proliferator-activated receptor- $\gamma$ (PPARG), SLC2A4, and RNA 18S.

\begin{tabular}{|c|c|c|}
\hline Gene & Primers & $\begin{array}{l}\text { Size } \\
\text { (bp) }\end{array}$ \\
\hline PPARG & $\begin{array}{l}\text { 5'-TCTCTCCGTAATGGAAGACC-3' (sense) } \\
5^{\prime} \text {-GCATTATGAGACATCCCCAC-3' (antisense) }\end{array}$ & 474 \\
\hline SLC2A4 & $\begin{array}{l}\text { 5'-ATCCTGATGACTGTGGCTCTGCT-3' (sense) } \\
\text { 5'-TCGTTCTCATCTGGCCCTAAATCA-3' } \\
\text { (antisense) }\end{array}$ & 433 \\
\hline rRNA $18 \mathrm{~S}$ & $\begin{array}{l}\text { 5'-GTAACCCGTTGAACCCCATT-3' (sense) } \\
5^{\prime} \text {-CCATCCAATCGGTAGTAGCG-3' (antisense) }\end{array}$ & 200 \\
\hline
\end{tabular}

SLC2A4 were $2 \mathrm{mmol} / \mathrm{l} \mathrm{MgCl}_{2}, 0.20 \mathrm{mmol} / \mathrm{l} \mathrm{dNTPs}, 2 \mathrm{U}$ of Taq DNA polymerase, and 30 pmol each primer. The PCR amplification was performed in the thermocycler, model PTC100 (MJ Research Inc., Watertown, MA, USA) and Mastercycler Personal (Eppendorf AG, Foster City, CA, USA). The PCR products were electrophoretically resolved on $2 \%$ agarose gel and stained with EtBr. The bands were evaluated using an image analyzer UN-SCAN-IT gel 4.1 (Silk Scientific Corporation) and normalized relative to the ribosomal mRNA $18 \mathrm{~S}$ PCR product.

\section{Statistical evaluation}

The number of subjects in this study was calculated, assuming $\alpha=0.05$ and $\beta=0.20$ and a difference between means of 0.25 and S.D. of 0.16 according to our previous studies (Bacallao et al. 2008, Fornes et al. 2010). The distribution of the data was analyzed by Kolmogorov-Smirnov test. The results were analyzed by Student's $t$-test or Mann-Whitney test. $P$ values $<0.05$ were considered significant. Statistical tests were performed using Graphpad for Windows version 5.0 Software, Inc. For the correlation study, the data showed normal distribution, and Pearson's test was used. A $P$ value $<0.05$ was considered significantly different.

\section{Declaration of interest}

The authors declare that there is no conflict of interest that could be perceived as prejudicing the impartiality of the research reported.

\section{Funding}

This work was supported by Fondo Nacional de Desarrollo Científico y Tecnológico (grant number 1095127) and Comisión Nacional de Investigación Científica y Tecnológica (grant number D-21060340).

\section{Acknowledgements}

The authors thank M D Armando Cortinez and Emiliano Soto (University of Chile Medical School) for their role in the recruitment of subjects and to Ketty Bacallao, $\mathrm{PhD}$ for laboratory assistance. We are also grateful to the women who donated tissue. 


\section{References}

Al-Khalili L, Forsgren M, Kannisto K, Zierath JR, Lönnqvist F \& Krook A 2005 Enhanced insulin-stimulated glycogen synthesis in response to insulin, metformin or rosiglitazone is associated with increased mRNA expression of GLUT4 and peroxisomal proliferator activator receptor gamma co-activator 1 . Diabetologia $\mathbf{4 8}$ 1173-1179.

Armoni M, Kritz N, Harel C, Bar-Yoseph F, Chen H, Quon MJ \& Karnieli E 2003 Peroxisome proliferator-activated receptor- $\gamma$ represses GLUT4 promoter activity in primary adipocytes, and rosiglitazone alleviates this effect. Journal of Biological Chemistry 278 30614-30623.

Armoni M, Harel C, Karni S, Chen H, Bar-Yoseph F, Ver RM, Quon MJ \& Karnieli E 2006 FOXO1 represses peroxisome proliferator-activated receptor- $\gamma 1$ and $-\gamma 2$ gene promoters in primary adipocytes. Journal of Biological Chemistry 281 19881-19891.

Armoni M, Harel C \& Karnieli E 2007 Transcriptional regulation of the GLUT4 gene: from PPAR- $\gamma$ and FOXO1 to FFA and inflammation. Trends in Endocrinology and Metabolism 18 100-107.

Asada S, Daitoku H, Matsuzaki H, Saito T, Sudo T, Mukai H, Iwashita S, Kako K, Kishi T, Kasuya Y et al. 2007 Mitogen-activated protein kinases, Erk and p38, phosphorylate and regulate FOXO1. Cellular Signalling 19 519-527.

Avellaira C, Villavicencio A, Bacallao K, Gabler F, Wells P, Romero C \& Vega M 2006 Expresión of molecules associated with tissue homeostasis in secretory endometria from untreated women with polycystic ovary síndrome. Human Reproduction 21 3116-3121.

Azziz R, Carmina E, Dewailly D, Diamanti-Kandarakis E, EscobarMorreale HF, Futterweit W, Janssen OE, Legro RS, Norman RJ, Taylor AE et al. 2006 Position statement: criteria for defining polycystic ovary syndrome as a predominantly hyperandrogenic syndrome: an androgen excess society guideline. Journal of Clinical Endocrinology and Metabolism 91 4237-4245.

Bacallao K, Leon L, Gabler F, Soto E, Romero C, Valladares L \& Vega M 2008 In situ estrogen metabolism in proliferative endometria from untreated women with polycystic ovarian syndrome with and without endometrial hyperplasia. Journal of Steroid Biochemistry and Molecular Biology 110 163-169.

Calle EE \& Kaaks R 2004 Overweight, obesity and cancer: epidemiological evidence and proposed mechanism. Nature Reviews. Cancer 4 579-591.

Castro A, Johnson MC, Anido M, Cortinez A, Gabler F \& Vega M 2002 Role of nitric oxide and bcl-2 family genes in the regulation of human endometrial apoptosis. Fertility and Sterility 78 587-595.

Cataldo N, Abbasi F, McLaughlin TL, Lamendola C \& Reaven GM 2001 Improvement in insulin sensitivity followed by ovulation and pregnancy in a woman with polycystic ovary syndrome who was treated with rosiglitazone. Fertility and Sterility 76 1057-1059.

Diamanti-Kandarakis E \& Papavassiliou AG 2006 Molecular mechanisms of insulin resistance in polycystic ovary syndrome. Trends in Molecular Medicine 12 324-332.

Dunaif A 1997 Insulin resistance and the polycyctic ovarian syndrome: mechanism and implications for pathogenesis. Endocrine Reviews 18 774-800.

Ehrmann DA, Liljenquist DR, Kasza K, Azziz R, Legro RS \& Ghazzi MN 2006 Prevalence and predictors of the metabolic syndrome in women with polycystic ovary syndrome. Journal of Clinical Endocrinology and Metabolism 91 48-53.

Fornes R, Ormazabal P, Rosas C, Gabler F, Vantman D, Romero C \& Vega M 2010 Changes in the expression of insulin signaling pathway molecules in endometria from PCOS women with or without hyperinsulinemia. Molecular Medicine 16 129-136.

Froment P \& Touraine P 2006 Thiazolidinediones and fertility in polycystic ovary syndrome (PCOS). PPAR Research 2006 1-8.

Froment P, Gizard F, Defever D, Staels B, Dupont J \& Monget P 2006 Peroxisome proliferator activated receptors in reproductive tissues: from gametogenesis to parturition. Journal of Endocrinology 189 199-209.

Giudice LC 2006 Endometrium in PCOS: implantation and predisposition to endocrine CA. Best Practice \& Research. Clinical Endocrinology \& Metabolism 20 235-244.
Gross DN, van den Heuvel APJ \& Birnbaum MJ 2008 The role of FoxO in the regulation of metabolism. Oncogene 27 2320-2336.

Jensterle M, Sebestjen M, Janez1 A, Prezelj J, Kocjan T, Keber I \& Pfeifer M 2008 Improvement of endothelial function with metformin and rosiglitazone treatment in women with polycystic ovary syndrome. European Journal of Endocrinology 159 399-406.

Jermendy G 2007 PPAR- $\gamma$ agonists - antidiabetic drugs with a potential role in the treatment of diseases other than diabetes. Diabetes Research and Clinical Practice 78 29-39.

Karnieli E \& Armoni M 2008 Transcriptional regulation of the insulin-responsive glucose transporter GLUT4 gene: from physiology to pathology. American Journal of Physiology. Endocrinology and Metabolism 295 38-45.

Legro RS, Zaino RJ, Demers LM, Kunselman A, Gnatuk C, Williams N \& Dodson W 2007 The effects of metformin and rosiglitazone, alone and in combination, on the ovary and endometrium in polycystic ovary syndrome. American Journal of Obstetrics and Gynecology 196 402.e1-402.e11.

Lengyel F, Vértes Z, Kovács KA, Környei JL, Sümegic B \& Vértes M 2007 Effect of estrogen and inhibition of phosphatidylinositol-3 kinase on Akt and FOXO1 in rat uterus. Steroids 72 422-428.

León L, Bacallao K, Gabler F, Romero C, Valladares L \& Vega M 2008 Activities of steroid metabolic enzymes in secretory endometria from untreated women with polycystic ovary syndrome. Steroids $\mathbf{7 3}$ 88-95.

Lessey BA, Killam AP, Metzger DA, Haney AF, Greene GL \& McCarty KS Jr 1988 Immunohistochemical analysis of human uterine estrogen and progesterone receptors throughout the menstrual cycle. Journal of Clinical Endocrinology and Metabolism 67 334-340.

Maliqueo M, Clementi M, Gabler F, Johnson M, Palomino A, Sir Peterman T \& Vega M 2003a Expression of steroid receptors and proteins related to apoptosis in endometria of women with polycystic ovary syndrome. Fertility and Sterility $\mathbf{8 0} 812-819$.

Maliqueo M, Atwater I, Lahsen R, Pérez-Bravo F, Angel B \& Sir-Petermann T 2003b Proinsulin serum concentrations in women with polycystic ovary syndrome: a marker of $\beta$-cell dysfunction? Human Reproduction 18 2683-2688.

Mioni R, Chiarelli S, Xamin N, Zuliani L, Granzotto M, Mozzanega B, Maffei P, Martini C, Blandamura S, Sicolo N et al. 2004 Evidence for the presence of glucose transporter 4 in the endometrium and its regulation in polycystic ovary syndrome patients. Journal of Clinical Endocrinology and Metabolism 89 4089-4096.

Nakae J, Oki M \& Cao Y 2008 The FoxO transcription factors and metabolic regulation. FEBS Letters $\mathbf{5 8 2} 54-67$.

Noyes R, Hertig A \& Rock J 1950 Dating the edometrial biopsy. Fertility and Sterility 1 3-5.

Ota K, Ito K, Suzuki T, Saito S, Tamura M, Hayashi S, Okamura K, Sasano H \& Yaegashi N 2006 Peroxisome proliferator-activated receptor gamma and growth inhibition by its ligands in uterine endometrial carcinoma. Clinical Cancer Research 12 4200-4208.

Picard F \& Auwerx J 2002 PPAR- $\gamma$ and glucose homeostasis. Annual Review of Nutrition 22 167-197.

Porter TF \& Scott JR 2005 Evidence-based care of recurrent miscarriage. Best Practice \& Research. Clinical Obstetrics \& Gynaecology 19 85-101.

Pugeat M, Ducluzeau PH \& Mallion-Donadieu M 2000 Association of insulin resistance with hyperandrogenia in women. Hormone Research 54 322-326.

Quezada S, Avellaira C, Johnson MC, Gabler F, Fuentes A \& Vega M 2006 Evaluation of steroid receptors, coregulators, and molecules associated with uterine receptivity in secretory endometria from untreated women with polycystic ovary syndrome. Fertility and Sterility 85 1017-1026.

Ricote M \& Glass CK 2007 PPARs and molecular mechanism of transrepression. Biochimica et Biophysica Acta $1771926-935$.

Salley KES, Wickham EP, Cheang KI, Essah PA, Karjane NW \& Nestler JE 2006 POSITION STATEMENT: glucose intolerance in polycystic ovary syndrome - a Position Statement of the Androgen Excess Society. Journal of Clinical Endocrinology and Metabolism 92 4546-4556.

Seto-Young D, Paliou M, Schlosser J, Avtanski D, Park A, Patel P, Holcomb K, Chang P \& Poretsky L 2005 Direct thiazolidinedione action in the human ovary: insulin-independent and insulin-sensitizing effects 
on steroidogenesis and insulin-like growth factor binding protein-1 production. Journal of Clinical Endocrinology and Metabolism 90 6099-6105.

Rotterdam ESHRE/ASRM-Sponsored PCOS and Consensus Workshop Group 2004 Revised consensus on diagnostic criteria and long-term health risk related to polycystic ovary syndrome. Fertility and Sterility $\mathbf{8 1}$ $19-25$.

Villavicencio A, Goyeneche A, Telleria C, Bacallao K, Gabler F, Fuentes A \& Vega M 2009 Involvement of Akt, Ras and cell cycle regulators in the potential development of endometrial hyperplasia in women with polycystic ovarian syndrome. Gynecologic Oncology 115 102-107.
Yu S \& Reddy JK 2007 Transcription coactivators for peroxisome proliferator-activated receptors. Biochimica et Biophysica Acta 1771 936-951.

Ziouzenkova O \& Plutzky J 2008 Retinoid metabolism and nuclear receptor responses: new insights into coordinated regulation of the PPAR-RXR complex. FEBS Letters 582 32-38.

Received 27 January 2010

First decision 15 March 2010

Accepted 20 April 2010 